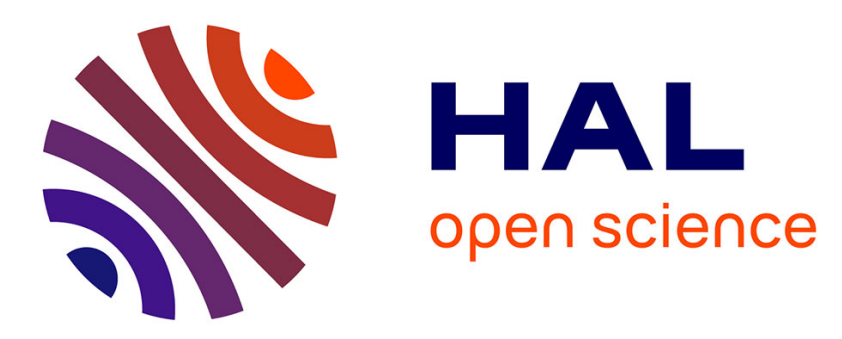

\title{
Ultrasmall theranostic gadolinium-based nanoparticles improve high-grade rat glioma survival
}

Sandrine Dufort, Geoffrey Appelboom, Camille Verry, Emmanuel L. Barbier, François Lux, Elke Bräuer-Krisch, Lucie Sancey, Steven D Chang, Michael Zhang, Stéphane Roux, et al.

\section{To cite this version:}

Sandrine Dufort, Geoffrey Appelboom, Camille Verry, Emmanuel L. Barbier, François Lux, et al.. Ultrasmall theranostic gadolinium-based nanoparticles improve high-grade rat glioma survival. Journal of Clinical Neuroscience, 2019, 67, pp.215-219. 10.1016/j.jocn.2019.05.065 • hal-02337558

\section{HAL Id: hal-02337558 https://hal.science/hal-02337558}

Submitted on 29 Oct 2019

HAL is a multi-disciplinary open access archive for the deposit and dissemination of scientific research documents, whether they are published or not. The documents may come from teaching and research institutions in France or abroad, or from public or private research centers.
L'archive ouverte pluridisciplinaire HAL, est destinée au dépôt et à la diffusion de documents scientifiques de niveau recherche, publiés ou non, émanant des établissements d'enseignement et de recherche français ou étrangers, des laboratoires publics ou privés. 
archives-ouvertes

\section{Ultrasmall theranostic gadolinium-based nanoparticles improve high-grade rat glioma survival}

Sandrine Dufort, Geoffrey Appelboom, Camille Verry, Emmanuel Barbier, François Lux, Elke Bräuer-Krisch, Lucie Sancey, Steven Chang, Michael Zhang, Stéphane Roux, et al.

\section{To cite this version:}

Sandrine Dufort, Geoffrey Appelboom, Camille Verry, Emmanuel Barbier, François Lux, et al.. Ultrasmall theranostic gadolinium-based nanoparticles improve high-grade rat glioma survival. Journal of Clinical Neuroscience, Elsevier, 2019, 67, pp.215-219. 10.1016/j.jocn.2019.05.065 . hal-02337558

\section{HAL Id: hal-02337558 \\ https://hal.archives-ouvertes.fr/hal-02337558}

Submitted on 29 Oct 2019

HAL is a multi-disciplinary open access archive for the deposit and dissemination of scientific research documents, whether they are published or not. The documents may come from teaching and research institutions in France or abroad, or from public or private research centers.
L'archive ouverte pluridisciplinaire HAL, est destinée au dépôt et à la diffusion de documents scientifiques de niveau recherche, publiés ou non, émanant des établissements d'enseignement et de recherche français ou étrangers, des laboratoires publics ou privés. 
Experimental study

\title{
Ultrasmall theranostic gadolinium-based nanoparticles improve high-grade rat glioma survival
}

\author{
Sandrine Dufort ${ }^{\mathrm{a}, 1}$, Geoffrey Appelboom ${ }^{\mathrm{b}, *}$, Camille Verry ${ }^{\mathrm{c}, \mathrm{d}}$, Emmanuel L Barbier ${ }^{\mathrm{d}}$, François Lux ${ }^{\mathrm{e}}$, \\ Elke Bräuer-Krisch $^{\mathrm{f}}$, Lucie Sancey ${ }^{\mathrm{e}}$, Steven D. Chang ${ }^{\mathrm{b}}$, Michael Zhang ${ }^{\mathrm{b}}$, Stéphane Roux ${ }^{\mathrm{g}}$, \\ Olivier Tillement ${ }^{\mathrm{e}}$, Géraldine Le Duc ${ }^{\mathrm{f}, 1}$
}

${ }^{a}$ Nano-H SAS, F38070 Saint-Quentin-Fallavier, France

${ }^{\mathrm{b}}$ Department of Neurosurgery Stanford Medical Center, Palo Alto 94304, CA, United States

' Grenoble Alpes University Hospital, Department of Radiotherapy, BP217, F38043 Grenoble cedex 9, France

d INSERM U1216, Grenoble Alpes University, Grenoble Institute of Neurosciences, F38000 Grenoble, France

e Institut Lumière Matière, UMR5306, Université Lyon1-CNRS, Université de Lyon, F69622 Villeurbanne, France

${ }^{\mathrm{f}}$ Biomedical Beamline, European Synchrotron Radiation Facility, CS40220, F38043 Grenoble Cedex 9, France

${ }^{\mathrm{g}}$ Institut UTINAM, UMR 6213 CNRS, Université de Franche-Comté, F25030 Besançon Cedex, France

\section{A R T I C L E I N F O}

\section{Article history:}

Received 27 October 2018

Accepted 27 May 2019

Available online $\mathrm{xxxx}$

\section{Keywords:}

Glioblastoma

Temozolomide

Theranostic

Nanoparticles

Radiosensitizers

Chemoradiation

\begin{abstract}
A B S T R A C T
We formulated an ultra-small, gadolinium-based nanoparticle (AGuIX) with theranostic properties to simultaneously enhance MRI tumor delineation and radiosensitization in a glioma model. The 9L glioma cells were orthotopically implanted in 10-week-old Fischer rats. The intra-tumoral accumulation of AGuIX was quantified using MRI T1-maps. Rats randomized to intervention cohorts were subsequently treated with daily temozolomide for five consecutive days before radiotherapy treatment. Collectively, a series of 32 rats were divided into untreated $(n=7)$, temozolomide-only $(n=7)$, temozolomide and MRT $(n=9)$, AGuIX and MRT $(n=7)$, and triple therapy (temozolomide, AGuIX NPs, and MRT; $n=9$ ) cohorts. AGuIX nanoparticles achieved a maximum intra-tumoral concentration (expressed as concentration of $\mathrm{Gd} 3+$ ) at $1 \mathrm{~h}$ after intravenous injection, reaching a mean of $227.9 \pm 60 \mu \mathrm{M}$. This was compared to concentrations of $10.5 \pm 9.2 \mu \mathrm{M}$ and $62.9 \pm 24.7 \mu \mathrm{M}$ in the contralateral hemisphere and cheek, respectively. There was a slower washout in the intra-tumor region, with sustained tumor-to-contralateral ratio of AGuIX, up to 14-fold, for each time point. The combination of AGuIX or temozolomide with MRT improved the median survival time (40 days) compared to the MeST of control rats (25 days) $(\mathrm{p}<0.002)$. There was a trend towards further increased survival when the three treatments were combined (MeST of 46 days). This study demonstrated the selective accumulation of AGuIX in high grade glioma, as well as the potential survival benefits when combined with chemoradiation.
\end{abstract}

\section{Introduction}

Glioblastoma multiforme (GBM) is the most common and aggressive form of high-grade glioma with 3 per 100,000 new cases per year and a median survival of 14 months, despite optimal surgical resection followed by postoperative radiotherapy and chemotherapy. Tumor almost invariably recurs at its original site, leading to a median survival of 1 year after diagnosis, and a 5 -year survival rate of 9.8\% [1]. The effect of radiation therapy (RT) on survival has been demonstrated in GBM patients treated

* Corresponding author at: Department of Neurosurgery, Stanford Hospital and Clinics, Palo Alto, CA 94304, United States.

E-mail address: ga@neuro-digital.com (G. Appelboom).

${ }^{1}$ Present affiliation: NH TherAguix SAS, F69100 Villeurbanne, France. with whole brain RT, although not without side effects. Further benefit has also not been seen from dose escalation [2,3]. Thus, new protocols aiming to maximize radiation potency to targeted tissue is paramount.

Radiation sensitizers are compounds that are given concurrently with RT in an effort to increase local therapeutic effect. Several classes of radiosensitizers have been studied but none have been approved for high grade gliomas [4].We have developed a new class of ultrasmall, theranostic $(3.0 \pm 1.0 \mathrm{~nm}$ size $)$ gadolinium (Gd)-based nanoparticle (AGuIX NPs) for theranostic applications, to improve radiographic delineation and increase the intratumoral dose-effect delivered by the particles beams [5-8]. High Z-elements are incorporated to enhance local radiation absorption and introduce harmful photons, photoelectrons, Auger electrons, 
Compton electrons and radical species [9]. The effect is a more efficient destruction of the tumor, without dose escalation to healthy tissue. Studies have demonstrated such efficacy when combining AGuIX NPs with radiation for glioblastoma [10,11], lung tumors [12], pancreatic adenocarcinoma [13,14], and multifocal intracranial melanoma metastases [15].

AGuIX NPs can also be used for MRI tumor delineation [16,17]. They are characterized by rapid clearance by normal tissue, high tumor-to-healthy tissue affinity ratios, and extravasation from normal blood vessels based on enhanced permeability and retention (EPR) effect [18-23]. Our nanotechnology showed superior contrast compared to other Gd chelates [24].

In this study, we aimed to quantify local AGuIX concentration in orthotopic glioma rat tumor after intravenous injection and to examine its synergistic effects on survival from combinations of temozolomide, AGuIX NPs and radiotherapy in the treatment of high-grade gliomas.

\section{Materials and methods}

\subsection{Gadolinium (Gd)-based AGuIX NPs}

The Gd-based AGuIX NPs were synthesized and characterized according to a previously described protocol [16,25]. Briefly, the NPs are synthesized through a top-down process and are made of $\mathrm{Gd}$ chelates (1,4,7,10-tetraazacyclododecane-1-glutaric acid$4,7,10$-triacetic acid, i.e. DOTAGA) covalently linked to a polysiloxane network core. During synthesis, $\mathrm{pH}$ was adjusted to $7.2 \pm 0.15$ and the final hydrodynamic diameter was precisely controlled to reach $3 \pm 1 \mathrm{~nm}$, favoring renal elimination. The $r_{1}$ value used for the MRI calculation was equal to $6 \mathrm{mM}^{-1} \cdot \mathrm{s}^{-1}(7 \mathrm{~T})$, while the $\mathrm{r}_{2} / \mathrm{r}_{1}$ ratio is $2.2(7 \mathrm{~T}$ ) (compared with 1.14 at $1.4 \mathrm{~T}$ ) [16]. More than $90 \%$ of the injected NPs is renally cleared within the first day after injection, allowing a safe elimination [26].

\section{Treatment and irradiation procedures}

\subsection{Animals}

All procedures related to animal care conformed to the Guidelines of the European and French Government with licenses 380,325 and B3818510002, and were approved by the Ethical Committee of the ESRF (ETHAX) and registered under number 01261.01 at French Ministry of Research.

\subsection{Brain tumor inoculation}

The 9L glioma (9LGS) cells were implanted in the brain of male 10-week-old Fisher 344 rats (Charles River, France) [27,28]. Anesthetized animals were placed on a stereotactic frame, and $10^{4}$ 9LGS cells suspended in $1 \mu \mathrm{L}$ DMEM $+1 \%$ penicillin/streptomycin were pushed manually within $30 \mathrm{~s}$ using a Hamilton syringe inserted into the right caudate nucleus $(3.5 \mathrm{~mm}$ lateral to the bregma, $6 \mathrm{~mm}$ depth below the skull surface). All time intervals stated in the manuscript are post implantation, i.e. D10 means 10 days after tumor implantation.

The rats were anesthetized by inhalation of $4 \%$ isoflurane in air followed by an intraperitoneal injection of xylazine/ketamine $64.5 / 5.4 \mathrm{mg} . \mathrm{kg}^{-1}$ for the glioma implantation, nanoparticle injection and irradiation. The rats were anesthetized by inhalation of $2.5 \%$ isoflurane in air for MRI examination. In any case, the eyes of the animals were embedded with a drop of Ocry-gel (TVM Laboratories, France) during the anesthesia to avoid dryness of the cornea.

\subsection{Treatments}

The AGuIX NPs were injected in the saphenous vein with either $1 \mathrm{~mL}$ of $100 \mathrm{~g} / \mathrm{L}$ AGuIX NPs in saline buffer for MRI examination or $1.4 \mathrm{~mL}$ of $40 \mathrm{~g} / \mathrm{L}$ for therapy. Temozolomide was delivered by intraperitoneal injection ( $1 \mathrm{~mL}$ containing $3.3 \mathrm{mg}$ of temozolomide) for 5 consecutive days, from day 6 to 10 after tumor implantation. The AGuIX NPs were intravenously injected at day $10,4 \mathrm{~h}$ before Microbeam Radiation Therapy (MRT) (Fig. 1). Animal weight was monitored daily during the 5 days of treatment with temozolomide, then weekly.

\subsection{MRI acquisitions}

MRI was performed on a $7 \mathrm{~T}$ scanner (Biospec 70/20, Bruker Avance III console, Germany - Grenoble MRI facility IRMaGE) equipped with a $660 \mathrm{mT} / \mathrm{m}$ gradient coil and volume transmit/surface receive radiofrequency coils. Animals were placed in the prone position. All images were acquired in the coronal orientation. The MRI protocol was composed of three sequences:

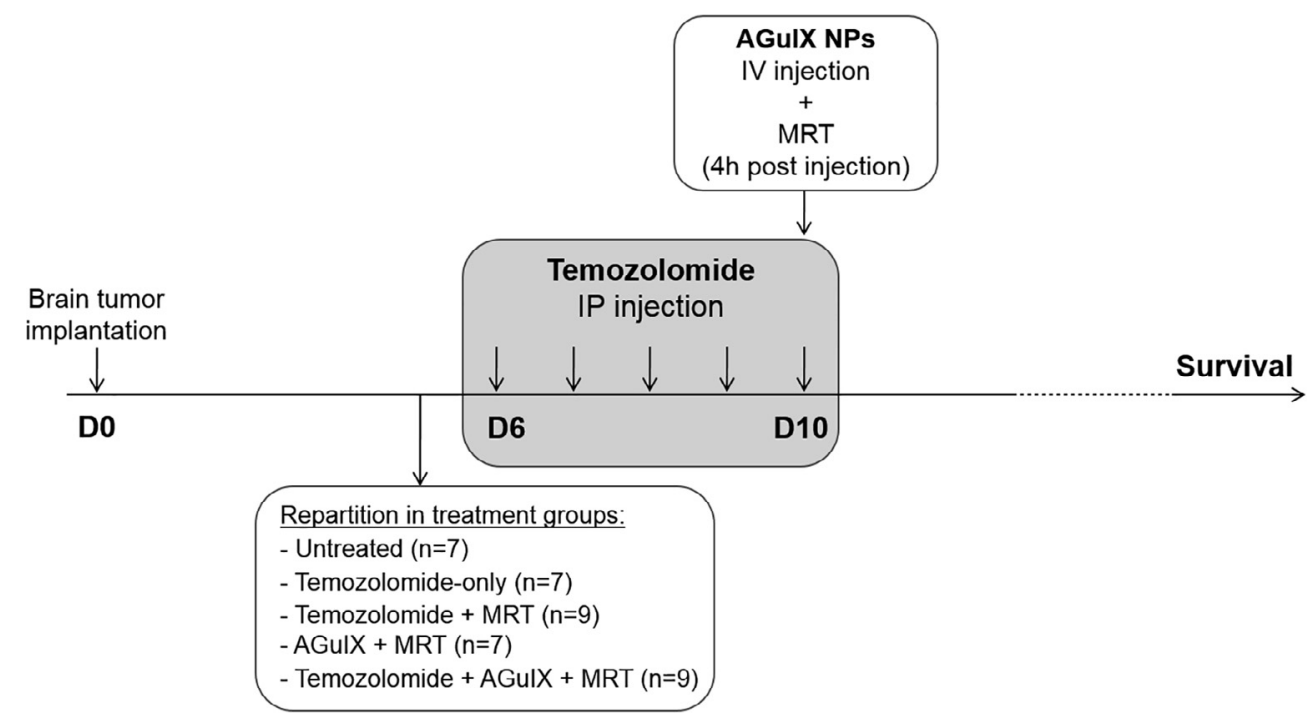

Fig. 1. Diagram of the therapeutic experimental protocol. 
- T2-weighted anatomical Rapid Acquisition with Refocused Echoes (RARE) images (repetition time (TR)/effective echo time (TE) $2500 / 40 \mathrm{~ms}$, number of average $(\mathrm{NA})=2$, slice thickness $=1 \mathrm{~mm}$, reconstruction voxel size $=117 \times 117 \times 1000 \mu \mathrm{m}$, field of view $(\mathrm{FOV})=3 \times 3 \mathrm{~cm}$ ) were used for tumor localization and evaluation of the tumor volume;

- $\mathrm{T}_{1}$-weighted spin-echo images (TR/TE 800/5 ms, NA $=4$, slice thickness $=1 \mathrm{~mm}$, reconstruction voxel size $=234 \times 234 \times$ $1000 \mu \mathrm{m}, \mathrm{FOV}=3 \times 3 \mathrm{~cm}$ ) were acquired to assess the spatial extent of the extravasation of the contrast agent;

- $\mathrm{T}_{1}$ maps (inversion recovery obtained with spin-echo planar imaging (EPI) sequence and 18 inversion times values in the range [35-7200] $\mathrm{ms}, \mathrm{TR} / \mathrm{TE}=18,000 / 20 \mathrm{~ms}, \mathrm{NA}=1$, slice thickness $=1 \mathrm{~mm}$, reconstruction voxel size $=234 \times 234 \times 1000 \mu \mathrm{m}$, FOV $=3 \times 3 \mathrm{~cm}$ ) were used to estimate the concentration in NPs in the tumor region.

The images from the three sequences were obtained from the same imaging locations.

First, a preliminary study was performed over three rats at D14 stage to confirm tumor maturity on MRI and to quantify AGuIX NPs in brain tumor, the contralateral hemisphere and the cheek muscles [27]. The rats were imaged as previously described before injection and at 1, 4, 7 and $24 \mathrm{~h}$ after injection of AGuIX NPs.

\subsection{MRI data processing E analysis}

MRI data were processed using homemade software developed in MATLAB (MathWorks Inc., Natick, MA, USA) to calculate concentration and create regions of interest (ROIs). For each MR image, ROIs were manually delineated in the tumor, contralateral brain and cheek muscle to measure the average signal. The ROIs defined on the $T_{2}$-weighted images were then extended to the others MRI sequences ( $T_{1}$-weighted and $T_{1}$ map images).

\subsection{AGuIX concentration}

The $T_{1}$ maps were obtained by fitting, pixel by pixel, the inversion recovery data with a 3-parameter, exponential recovery, model [29]. The concentration of $\mathrm{Gd}^{3+}$ was calculated using the relaxation time determined on the $T_{1}$ maps, according to the formula

$$
\left[G d^{3+}\right]=\frac{1}{r_{1}}\left(\frac{1}{T_{1}(t)}-\frac{1}{T_{1}(t 0)}\right)
$$

where $\mathrm{T}_{1}(\mathrm{t} 0)$ is the relaxation time before AGuIX injection (in seconds), $\mathrm{T}_{1}(\mathrm{t})$ is the relaxation time after injection, and $\mathrm{r}_{1}$ is the relaxivity per $\mathrm{Gd}^{3+}$ in AGuIX NPs at $7 \mathrm{~T}\left(6 \mathrm{mM}^{-1} \cdot \mathrm{s}^{-1}\right)[16]$.

\subsection{Radiation source and microbeam radiation therapy (MRT) setup}

Irradiations were performed at the ID17 Biomedical Beamline of the European Synchrotron Radiation Facility (Grenoble, France) using X-rays emitted tangentially from electron bunches circulating in a storage ring. The wiggler source produces a white spectrum of photons which extends after filtration (Be $(0.5 \mathrm{~mm}), \mathrm{C}$ $(1.5 \mathrm{~mm}), \mathrm{Al}(1.5 \mathrm{~mm})$ and $\mathrm{Cu}(1.0 \mathrm{~mm}))$ from 50 to $350 \mathrm{keV}$ (mean energy of $90 \mathrm{keV}$ ). The quasi-laminar beam is spatially fractionated into an array of microbeams by using an adjustable multislit collimator positioned $41.7 \mathrm{~m}$ from the photon source and $100 \mathrm{~cm}$ upstream from the head of the animals. Upstream from the multislit collimator, the dose rate within a homogenous field of $10 \mathrm{~mm} \times 10 \mathrm{~mm}$ was approximately $90 \mathrm{~Gy} \mathrm{~s}^{-1} \cdot \mathrm{mA}^{-1}$. Downstream the multislit collimator, the peak entrance dose within the microbeam was targeted for $72 \mathrm{~Gy} \mathrm{~s}^{-1} \cdot \mathrm{mA}^{-1}$.

\subsection{In vivo irradiation methods}

Ten days after tumor inoculation, the animals were positioned prone on a Kappa-type goniometer (Huber, Germany) in front of the X-rays source, on a home-made Plexiglas frame, and the alignment into the beam was performed using live cameras. The contention of the rats was performed by a teeth bar, while animals were under anesthesia. They received a lateral irradiation, from their anatomically right side to their left. Then, a $90^{\circ}$ angle was applied to the motorized goniometer and the second irradiation was performed in the anatomically anteroposterior direction. The field of irradiation was fixed at $10.5 \mathrm{~mm}$ height and $8 \mathrm{~mm}$ wide and was centered at the theoretical center of the tumor (i.e. $3.5 \mathrm{~mm}$ lateral to the bregma, $6 \mathrm{~mm}$ deep from the skull in the right hemisphere). The microbeams were $50 \mu \mathrm{m}$ wide with an on-center distance fixed at $211 \mu \mathrm{m}$. The total irradiation procedure lasted about 2 min. Animal immobility during exposure was checked on three control video screens located in the control hutch. A series of 32 rats was divided into untreated rats $(n=7)$, temozolomidetreated rats $(n=7)$, temozolomide and MRT-treated rats $(n=9)$, AGuIX NP and MRT-treated rats $(n=7)$, and triple therapy-treated (temozolomide, AGuIX NP, and MRT) rats $(n=9)$. A $4 \mathrm{~h}$ interval was required between NP injection and MRT based on results in previous studies $[10,30]$. The spatial configuration of the microbeams was checked by radiochromic films (Gafchromic, HD-810).

\subsection{Survival analysis}

The rats were followed up at the animal facility after the irradiation. At a later tumor stage, rats were euthanized by intra-cardiac injection of pentobarbital sodium within the day before their anticipated death as judged by clinical signs. Some of them were found dead. The time between implantation and death was recorded as survival time (one day was added for euthanized rats). The survivals of animals were represented on Kaplan-Meier curves and compared using the log-rank test, and the Median Survival Time (MeST) post-implantation was calculated. The increase in lifespan in percent (ILS) characterizes the difference between median survival time for treated and untreated rats divided by the median survival time for untreated rats.

\section{Results}

\subsection{Distribution and quantification of AGuIX NPs in brain tumors}

Qualitative visualization on $\mathrm{T}_{1}$-weighted MRI follow-up of the AGuIX NPs distribution in 9L-glioma bearing rats identified very strong contrast enhancement within engrafted tumor by the first time-point, $1 \mathrm{~h}$ after the IV injection. No signal was seen before AGuIX NPs administration. Tumor enhancement remained entirely visible up to $24 \mathrm{~h}$ after administration, while the NPs were almost completely eliminated from the contralateral brain region (Fig. 2A), and was significantly greater than all comparative controls $(p<0.01)$. Following this period, tumor contrast gradually declined, implying AGuIX NP clearance.

The quantification of actual Gd contained in administered AGuIX NPs, and the calculated Gd concentration obtained from $\mathrm{T}_{1}$ maps, matched the qualitative image analysis (Fig. 2B). Maximal intra-tumoral Gd concentration, reached a mean $227.9 \pm 60 \mu \mathrm{M}$ at $1 \mathrm{~h}$ after injection, and measured $65.2 \pm 23.2 \mu \mathrm{M}, 29.8 \pm 8.3 \mu \mathrm{M}$ and $15.1 \pm 0.9 \mu \mathrm{M}$, at $4 \mathrm{~h}, 7 \mathrm{~h}$ and $24 \mathrm{~h}$ respectively (Fig. 2C). Gd concentration was noted to decrease in the contralateral brain and cheek muscle, consistently with slower washout. Tumor-tocontralateral hemisphere $(\mathrm{T} / \mathrm{C})$ ratio of AGuIX concentrations achieved reached 21.6 at $1 \mathrm{~h}$ after administration and remained up to 14-fold higher for each time point. 

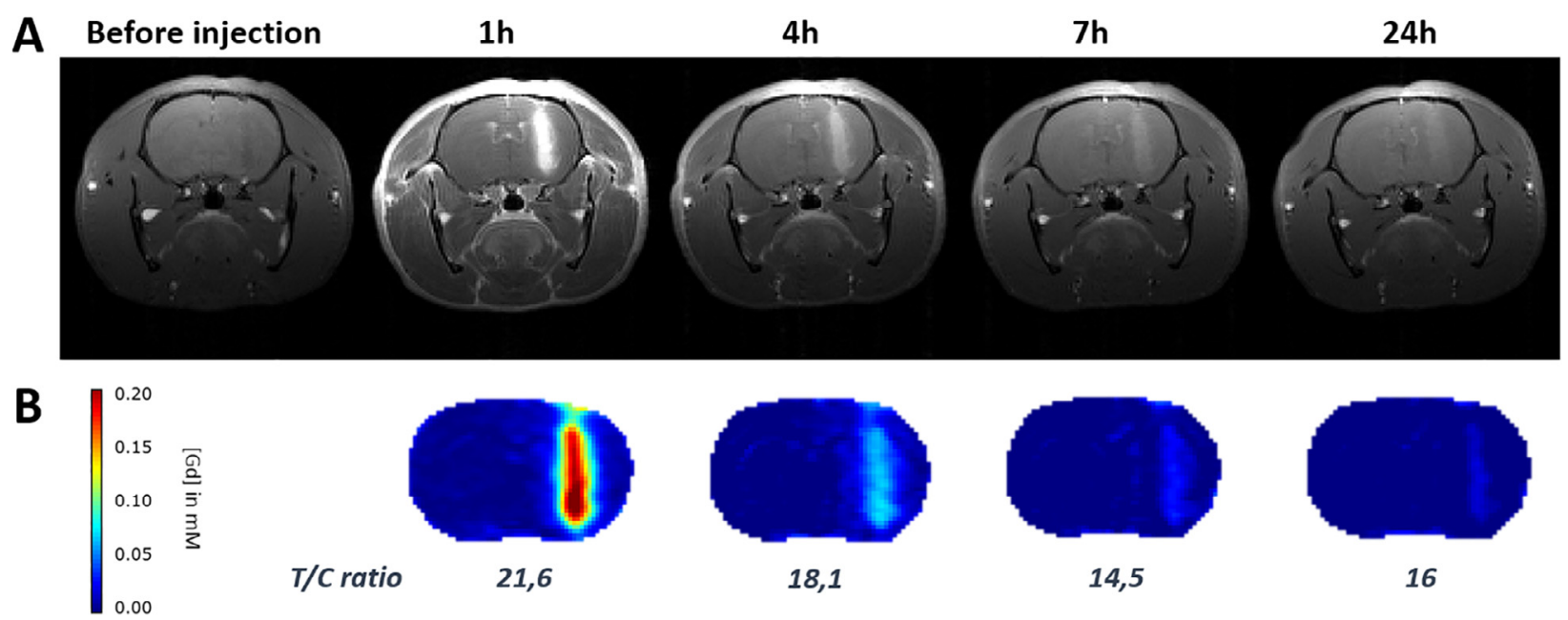

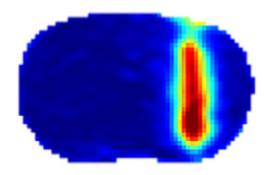

$T / C$ ratio
21,6

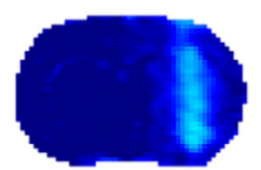

18,1

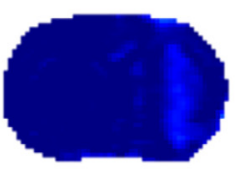

14,5

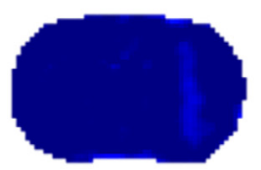

16

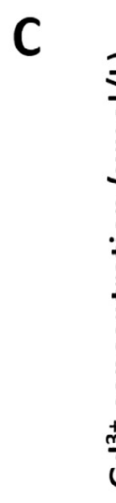

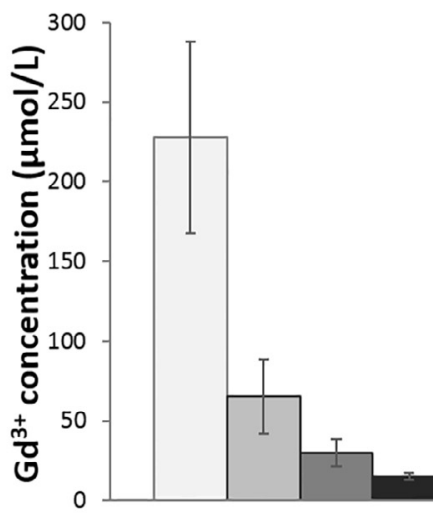

Tumor $\square 1 \mathrm{~h}$

$\square 4 \mathrm{~h}$

$\square 7 \mathrm{~h}$

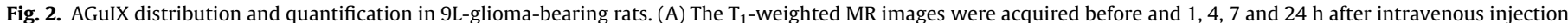

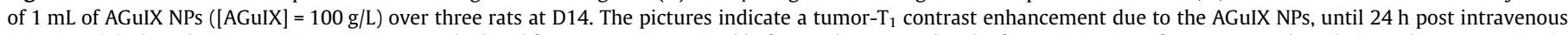

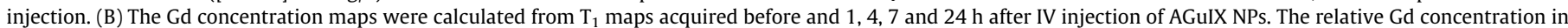

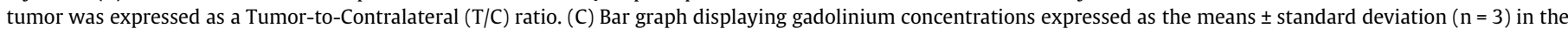
tumor and contralateral regions.

\subsection{Therapeutic efficacy of the combination of AGuIX NPs,} temozolomide and radiation therapy for the management of brain tumors

The radiosensitizing efficacy of the NPs combined with radiation therapy was already demonstrated in the 9L-glioma-rat model $[10,11,24,30]$. When further evaluating the therapeutic potential of AGuIX NPs, we saw that a combination of AGuIX or temozolomide with MRT improved the median survival time (40 days) compared to the MeST of control rats ( 25 days) $(p<0.002)$. The increase of survival further demonstrated a trend towards improved survival when the three treatments were combined such that MeST was 46 days, compared to AGuIX + MRT and temozolomide + MRT respectively ( $p=0.1$ and 0.137 ; Fig. 3 ).

\section{Discussion}

Since the publication of the EORTC trial, several pharmacological strategies have been tested with the objective of modulating tumor radiosensitivity and enhancing radiotherapy. To date, only marginal or non-existent clinical benefits have been obtained over standard strategy. Two randomized trials, have failed to enhance tumor control and survival in patients treated with radiation dose escalation (60 Gy followed by a $10 \mathrm{~Gy}$ tumor boost) [2,3]. Similarly, most radiosensitization by molecularly targeted agents is not

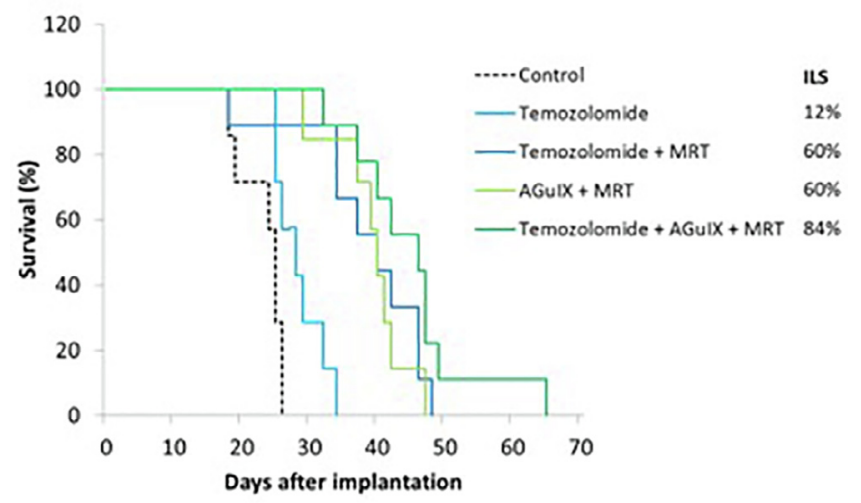

Fig. 3. Survival curve comparison obtained on 9L-glioma bearing rats.

specific to tumor cells, and the toxicity to normal tissues remains a limitation to these pharmacological strategies.

Here, we confirmed our ability to create both a therapeutic (survival enhancing) and diagnostic (tumor delineating) nanoparticle that can easily be injected intravenously. Our data suggest the selective accumulation of AGuIX NPs in brain tumors can provide a $15 \%$ survival improvement over the standard temozolomide and radiation regimen. It has been shown that ionizing radiation not only disrupts tumor cells, but also induces a combination of 
collateral damages i.e. disruption of tumor angiogenesis, bloodbrain barrier, neuroglial cells, and local inflammation [31-34]. Thus, we hypothesize that AGuIX NPs enhances ionizing radiation's tumoricidal properties locally but will also act as a chemotherapy enhancer through blood brain barrier and angiogenesis disruption.

Technological advances have allowed the emergence of high precision radiotherapy with the integration of 3D imaging. Gadolinium is already a well-studied and incorporated heavy atom for biomedical and therapeutic applications [10,14,35-37]. In some of our previous work, AGuIX was compared to FDA-approved gadolinium chelates and demonstrated a higher uptake and retention time by tumors allowing better contrast properties $[30,35]$. Based on these properties, AGuIX may allow for a more precise tumor delineation on MRI via a passive accumulation within the tumor due to the EPR effect. Such volume targeting is perhaps particularly important to promote local tumor control by irradiative effects that are not achievable by external beam-dose escalation alone or without introducing toxicities to normal tissue $[2,3,10,30]$.

In conclusion, in this study we confirm that AGuIX NPs selectively accumulate in glioma, and may have a potentiating effect on survival when administered with standard of care temozolomide and radiotherapy.

\section{Sources of support}

This project was supported by Nano-H S.A.S. and the French National Research Agency [grant numbers ANR-11-NANO-017 TheraGuIMA, ANR-12-RPIB-0010 MULTIMAGE]. The Grenoble MRI facility IRMaGE was supported by the French program "Investissement d'Avenir" run by the "Agence Nationale pour la Recherche" [grant number ANR-11-INBS-0006].

Authors F. Lux and O. Tillement are authors of patent WO2011/135101. G. Le Duc and O. Tillement are authors of patent W02009/053644. These patents protect the nanoparticles described in this publication: AGuIX. S. Dufort is an employee from Nano-H S.A.S. that is developing AGuIX. S. Dufort and G. Le Duc are employees from NH TherAguix S.A.S. that is evaluating the clinical applications of AGuIX.

\section{Appendix A. Supplementary data}

Supplementary data to this article can be found online at https://doi.org/10.1016/j.jocn.2019.05.065.

\section{References}

[1] Stupp R, Hegi ME, Mason WP, van den Bent MJ, Taphoorn MJ, Janzer RC, et al. Effects of radiotherapy with concomitant and adjuvant temozolomide versus radiotherapy alone on survival in glioblastoma in a randomised phase II study: 5-year analysis of the EORTC-NCIC trial. Lancet Oncol 2009:10:459-66.

[2] Chang CH, Horton J, Schoenfeld D, Salazer O, Perez-Tamayo R, Kramer S, et al. Comparison of postoperative radiotherapy and combined postoperative radiotherapy and chemotherapy in the multidisciplinary management of malignant gliomas. A joint Radiation Therapy Oncology Group and Eastern Cooperative Oncology Group study. Cancer 1983;52:997-1007.

[3] Nelson DF, Diener-West M, Horton J, Chang CH, Schoenfeld D, Nelson JS. Combined modality approach to treatment of malignant gliomas-reevaluation of RTOG 7401/ECOG 1374 with long-term follow-up: a joint study of the Radiation Therapy Oncology Group and the Eastern Cooperative Oncology Group. NCI Monogr 1988:279-84.

[4] Stupp R, van den Bent MJ, Hegi ME. Optimal role of temozolomide in the treatment of malignant gliomas. Curr Neurol Neurosci Rep 2005;5:198-206.

[5] Brauer-Krisch E, Serduc R, Siegbahn EA, Le Duc G, Prezado Y, Bravin A, et al. Effects of pulsed, spatially fractionated, microscopic synchrotron X-ray beams on normal and tumoral brain tissue. Mutat Res 2010;704:160-6.

[6] Kobayashi K, Usami N, Porcel E, Lacombe S, Le Sech C. Enhancement of radiation effect by heavy elements. Mutat Res 2010;704:123-31.

[7] McMahon SJ, Mendenhall MH, Jain S, Currell F. Radiotherapy in the presence of contrast agents: a general figure of merit and its application to gold nanoparticles. Phys Med Biol 2008;53:5635-51.
[8] Pradhan AK, Nahar SN, Montenegro M, Yu Y, Zhang HL, Sur C, et al. Resonant Xray enhancement of the Auger effect in high-Z atoms, molecules, and nanoparticles: potential biomedical applications. J Phys Chem A 2009;113:12356-63.

[9] McMahon SJ, Hyland WB, Muir MF, Coulter JA, Jain S, Butterworth KT, et al. Biological consequences of nanoscale energy deposition near irradiated heavy atom nanoparticles. Sci Rep 2011;1:18.

[10] Le Duc G, Miladi I, Alric C, Mowat P, Brauer-Krisch E, Bouchet A, et al. Toward an image-guided microbeam radiation therapy using gadolinium-based nanoparticles. ACS Nano 2011;5:9566-74.

[11] Verry C, Dufort S, Barbier EL, Montigon O, Peoc'h M, Chartier P, et al. MRIguided clinical 6-MV radiosensitization of glioma using a unique gadoliniumbased nanoparticles injection. Nanomedicine (Lond) 2016.

[12] Dufort S, Bianchi A, Henry M, Lux F, Le Duc G, Josserand V, et al. Nebulized gadolinium-based nanoparticles: a theranostic approach for lung tumor imaging and radiosensitization. Small 2015;11:215-21.

[13] Detappe A, Kunjachan S, Rottmann J, Robar J, Tsiamas P, Korideck H, et al. AGuIX nanoparticles as a promising platform for image-guided radiation therapy. Cancer Nanotechnol 2015;6:4.

[14] Detappe A, Kunjachan S, Sancey L, Motto-Ros V, Biancur D, Drane P, et al. Advanced multimodal nanoparticles delay tumor progression with clinical radiation therapy. J Control Release 2016;238:103-13.

[15] Kotb S, Detappe A, Lux F, Appaix F, Barbier EL, Tran V-L, et al. Gadoliniumbased nanoparticles and radiation therapy for multiple brain melanoma metastases: proof of concept before phase I trial. Theranostics 2016;6:418-27.

[16] Lux F, Mignot A, Mowat P, Louis C, Dufort S, Bernhard C, et al. Ultrasmall rigid particles as multimodal probes for medical applications. Angew Chem Int Ed Engl 2011;50:12299-303.

[17] Sancey L, Lux F, Kotb S, Roux S, Dufort S, Bianchi A, et al. The use of theranostic gadolinium-based nanoprobes to improve radiotherapy efficacy. Br J Radiol 2014;87:20140134.

[18] Bergers G, Benjamin LE. Tumorigenesis and the angiogenic switch. Nat Rev Cancer 2003;3:401-10.

[19] Iyer AK, Khaled G, Fang J, Maeda H. Exploiting the enhanced permeability and retention effect for tumor targeting. Drug Discov Today 2006;11:812-8.

[20] Jang SH, Wientjes MG, Lu D, Au JL. Drug delivery and transport to solid tumors. Pharm Res 2003:20:1337-50.

[21] Maeda H, Sawa T, Konno T. Mechanism of tumor-targeted delivery of macromolecular drugs, including the EPR effect in solid tumor and clinical overview of the prototype polymeric drug SMANCS. J Control Release 2001;74:47-61.

[22] Noguchi Y, Wu J, Duncan R, Strohalm J, Ulbrich K, Akaike T, et al. Early phase tumor accumulation of macromolecules: a great difference in clearance rate between tumor and normal tissues. Jpn J Cancer Res 1998;89:307-14.

[23] Seymour LW, Miyamoto Y, Maeda H, Brereton M, Strohalm J, Ulbrich K, et al. Influence of molecular weight on passive tumour accumulation of a soluble macromolecular drug carrier. Eur J Cancer 1995;31A:766-70.

[24] Le Duc G, Roux S, Paruta-Tuarez A, Dufort S, Brauer E, Marais A, et al. Advantages of gadolinium based ultrasmall nanoparticles vs molecular gadolinium chelates for radiotherapy guided by MRI for glioma treatment. Cancer Nanotechnol 2014;5:4.

[25] Mignot A, Truillet C, Lux F, Sancey L, Louis C, Denat F, et al. A top-down synthesis route to ultrasmall multifunctional Gd-based silica nanoparticles for theranostic applications. Chemistry 2013;19:6122-36.

[26] Sancey L, Kotb S, Truillet C, Appaix F, Marais A, Thomas E, et al. Long-term in vivo clearance of gadolinium-based AGuIX nanoparticles and their biocompatibility after systemic injection. ACS Nano 2015;9:2477-88.

[27] Bouchet A, Bidart M, Miladi I, Le Clec'h C, Serduc R, Coutton C, et al. Characterization of the 9L gliosarcoma implanted in the Fischer rat: an orthotopic model for a grade IV brain tumor. Tumour Biol 2014;35:6221-33.

[28] Benda P. Someda K, Messer J, Sweet WH. Morphological and immunochemical studies of rat glial tumors and clonal strains propagated in culture. J Neurosurg 1971;34:310-23.

[29] Barbier EL, Liu L, Grillon E, Payen JF, Lebas JF, Segebarth C, et al. Focal brain ischemia in rat: acute changes in brain tissue T1 reflect acute increase in brain tissue water content. NMR Biomed 2005;18:499-506.

[30] Dufort S, Le Duc G, Salome M, Bentivegna V, Sancey L, Brauer-Krisch E, et al. The high radiosensitizing efficiency of a trace of gadolinium-based nanoparticles in tumors. Sci Rep 2016;6:29678.

[31] Belka C, Budach W, Kortmann RD, Bamberg M. Radiation induced CNS toxicity-molecular and cellular mechanisms. Br J Cancer 2001;85:1233-9.

[32] Kolesnick R, Fuks Z. Radiation and ceramide-induced apoptosis. Oncogene 2003;22:5897-906.

[33] Nordal RA, Wong CS. Molecular targets in radiation-induced blood-brain barrier disruption. Int J Radiat Oncol Biol Phys 2005;62:279-87.

[34] Rola R, Raber J, Rizk A, Otsuka S, VandenBerg SR, Morhardt DR, et al. Radiationinduced impairment of hippocampal neurogenesis is associated with cognitive deficits in young mice. Exp Neurol 2004;188:316-30.

[35] Bianchi A, Dufort S, Lux F, Fortin PY, Tassali N, Tillement O, et al. Targeting and in vivo imaging of non-small-cell lung cancer using nebulized multimodal contrast agents. Proc Natl Acad Sci U S A 2014;111:9247-52.

[36] Caravan P, Ellison JJ, McMurry TJ, Lauffer RB. Gadolinium(III) chelates as MRI contrast agents: structure, dynamics, and applications. Chem Rev 1999;99:2293-352.

[37] Sherry AD, Caravan P, Lenkinski RE. Primer on gadolinium chemistry. J Magn Reson Imaging 2009;30:1240-8. 